\title{
IMPACT OF SOCIO-ECONOMIC DISPARITIES ON REGIONAL PLANNING AS A RESULT OF THE COVID-19 PANDEMIC
}

DOI: https://doi.org/10.18509/GBP210545i

UDC: $711.16: 30 / 33]:[616.98: 578.834(497.2)$

\author{
Metodi Ivanov \\ Sofia University „St. Kliment Ohridski“, Faculty of Geology and Geography, Department \\ "Regional Development", Sofia, Bulgaria
}

\begin{abstract}
The purpose of this report is to identify the deepening socio-economic disparities resulting from the COVID-19 pandemic. Based on an analysis of the existing problems in the demographic and socio-economic development of the municipalities in the Republic of Bulgaria, the emphasis is on opportunities to stimulate the regions and their gradual economic and social recovery to pre-pandemic levels. Attention will also be paid to the strategic planning for the reconstruction of the regions and the projected development for reducing the inequalities of the territorial-administrative units in the country in the medium and long term. In the decade to 2030 on the agenda in Bulgaria will be the need for territorial and administrative reform in line with the demographic and socio-economic situation of the country. In addition, the next programming period 20212027. Efforts will be focused entirely on stimulating recovery opportunities from the COVID-19 pandemic and the expected financial and economic crisis. Conducting any study to identify the problems arising from the COVID-19 pandemic in the field of regional development would help to implement an effective regional policy, both by the central executive and by local governments. For the restoration and normalization of the socio-economic relations, special attention should be paid to the improvement of the process related to the development of strategies for territory management and utilization of the areas adjacent to the lands of lagging municipalities. On the other hand, it is necessary to perform a comprehensive analysis in order to assess the development of municipalities in the Republic of Bulgaria and to determine trends and prospects for recovery and catching up with the regions in the European Union. This process presupposes, on the one hand, the development and testing of new assessment models, and, on the other hand, the reorganization of the management of the national territory and its constituent territorial-administrative divisions. As a result of the COVID-19 pandemic, discussions on redefining the concepts related to the deepening disparities between the individual territorial-administrative units should be brought to the forefront, rethinking a number of existing programs and strategies in the assessment of the planned, expected and achieved results from the program financing with funds from the structural funds of the European Union and the provided financing and / or co-financing from the central budget of the country.
\end{abstract}

Keywords: urban planning, regional economic growth, regional development, spatial planning

\section{INTRODUCTION}

In the coming years, the main prerequisite for the creation and development of a sustainable competitive economy will be based on the capabilities and capacity of the 
national economy to cope with external shocks, adapting as quickly as possible to changes in its environment. Definitely, the economic impact of the pandemic will develop over a longer period of time, and we can expect a significant part of active business to fail in its desire for faster recovery, although in many countries this failure is delayed by stimulating government policies and subsidies provided. The looming economic crisis will undoubtedly lead to some long-standing changes in the way people and companies move, organize and operate. Particular attention should be paid to the global processes of digital transformation, which can be seen both as a threat and as an opportunity for a country like Bulgaria. The problem for a country like Bulgaria is related to the continuing slow pace of digitalization of its economy, which risks increasing its backwardness, both regionally and globally. For this reason, it is extremely important for the executive to take a number of steps towards building the necessary digital infrastructure, a process that must be accompanied by the provision of opportunities to build the required modern digital skills of the population. As a result of the COVID-19 pandemic, a discussion will have to be launched on rethinking the role of the education system in the information society. Especially considering that the 21 st century one gets instant access to any information. On the other hand, Bulgaria will have to focus significant efforts and resources on creating and providing a favorable environment for the development of innovative enterprises. This means that, as a matter of priority, the country will have to promote the digitalization of economic activity and the introduction of e-government in order to achieve certain prospects for catching up with its significant lag behind other EU member states.

\section{Main problems in identifying and planning the socio-economic potential for the reconstruction of the regions}

In order to achieve a strong economic development of the regions in the country after the end of the COVID-19 pandemic and to achieve economic growth that reaches levels of over $5 \%$ on average per year, the central executive authorities will have to implement a series of reforms to improve both the institutional framework and to create conditions for efficiency gains. In addition, regional opportunities should be planned to increase investor interest and activity and attract foreign direct investment in the lagging regions of the country. In this regard, priority should be given to specific integrated measures by central executive bodies, as well as by local governments to attract foreign direct investment to the lagging socio-economic regions in the country, especially in smaller municipalities. At the beginning of the pandemic and the declared state of emergency in the Republic of Bulgaria, the current account deficit increased to EUR 40 million in March 2020, as compared to March 2019, when it was EUR 25.2 million. As for the first quarter of 2020, the current account is positive and amounts to EUR 501.6 million, with a surplus of EUR 229.9 million for the first quarter of 2019. There is a decrease in exports of Bulgarian goods by 140.3 million euros $(5.9 \%)$ on an annual basis, which is probably due to the emergency situation related to the pandemic of COVID-19.

While the balance on the current and capital account of Bulgaria in September 2020 is negative and amounts to 116.3 million euros, while compared to September 2019, when it has a surplus of 432 million euros. For the first nine months of 2020, its current and capital account is in surplus of 1.3908 billion euros, which is half of the surplus for the same period in 2019, when it amounted to 2.7806 billion euros. For the nine months of 2020 foreign direct investment amounted to a total of 729.6 million euros, with a contraction of foreign direct investment in the country by $30.9 \%$ compared to the same 
period in 2019, where foreign direct investment in the country amounted to 1,0563 billion. While the data for January 2021 show that the trade balance is negative at EUR 33.1 million ( $0.1 \%$ of GDP) with a deficit of EUR 79.2 million ( $0.1 \%$ of GDP) for January 2020. A, exports for January 2021 decreased by $3.6 \%$ or 89.9 million euros and is 2397 million euros, while compared to January 2020 when it was 2486.9 million euros. From the above data it is clear that the process of economic recovery and reaching pre-crisis levels will take considerable time, and we can expect that the recovery period of the country's economy will begin probably in 2022. Of course, the very process of economic recovery must be seen as a function of limiting the economic activity of enterprises in the current 2021. as a result of the continuing restrictions for economic entities related to the still uncontrolled situation with the COVID-19 pandemic in the first quarter of 2021, and it seems that the normalization of socio-economic life in the country will probably occur only in 2022, as to achieve economic recovery in the country, it must be planned in parallel with recovery processes to eliminate economic imbalances between regions and stimulate economic activity of enterprises. Expectations of a continued decline in private investment as a result of the ongoing crisis will be monitored until the right conditions are created for a gradual recovery of European markets. And, in order to achieve accelerated economic growth in the individual regions of the country, the administration's efforts during the ongoing crisis should be aimed at identifying and overcoming obstacles to possible investor interest in the individual regions of the country, paying special attention to strong socio-economically lagging regions. The creation of conditions for the faster recovery of the country's economy must be accompanied by the preparation of a specific strategic action plan, which will contain specific measures, including both changes in the regulatory framework, aimed not only at further easing the conditions for doing so of business in the country and stimulating the process of recovery of economic entities, but the measures should be aimed at creating conditions for attracting and increasing the share of foreign direct investment in the least developed regions of the country. A crucial part of the policies for planning of the recovery process from the Covid-19 pandemic is ,the reduction of vulnerability, which is related to the susceptibility of human development: human life, economy, social organization, and the physical aspects of the environment. Although public and economic vulnerability are perceived as the most important components of vulnerability, it is very important to take into account the significance of the biophysical basis for human life - the environmental and physical aspects of vulnerability and to deal with them in an integrated way. The vulnerability is integrally analyzed by its factors (exposure, susceptibility and resilience) and dimensions (social, economic, environmental and physical). The integrated vulnerability of a territory is measured as a combination of the factors listed above. All of them can be represented by a set of indicators, whose selection should be reasonable and well-grounded. The set of indicators should allow measurement of the vulnerability factors for each of the vulnerability dimensions"[1]. „The social vulnerability represent the socio-economic aspects of vulnerability, for instance, demographic structure of the population (age, education, occupation, awareness and access to information, family structure, etc.), organization of the population and communities, etc. The cultural-political vulnerability is related to the cultural heritage exposed to risk (physical and metaphysical cultural wealth), and the institutional strength of the political systems (trust in governmental structures, governmental support to disaster risk management, transparency of policies and systems, etc.). The economic vulnerability deals with the exposure of economic activities at risk, 
e.g. spatial location of economic activities, production of goods and services, etc. Environmental vulnerability reflects the fragility and exposure of natural elements at risk: ecosystems, protected areas, sensitive environments such as forests, wetlands, biodiversity, etc. The physical vulnerability represents the strength and design features of key infrastructural elements at risk, i.e. critical infrastructure (emergency reaction centres, shelters, medical facilities, social and cultural meeting points, etc.), transport infrastructure (roads, railways, airports, harbours, etc.), and facilities and life lines (supply and communication networks, etc.)[2]. The COVID-19 pandemic has produced several unprecedented effects around the world and has adversely affected the transport sector, which has experienced a drastic reduction in passenger traffic across all different modes of transport. With physical interaction being the key medium perpetuating the spread of the virus, government decisions have been pivotally centered on either discrete decisions or combinations of decisions to curtail or block mobility [3], [4].

\section{Problems with the implementation of the planning process}

Problems with the implementation of the planning process may include, first of all, the development of basic tools, taking into account existing and future services, such as accessibility and parking management in busy central urban areas, integration of public transport schedules, etc. On the other hand, the difficulties of smart planning are related to the determination of quantitative and measurable indicators to show the level of change. „Cities are centers of modern societies and civilization. They create a lot of value, but a lot of resources are consumed. The city itself is a multifunctional and complex object that can be represented as a demographic, ecological, transport, administrative-territorial and industrial production system. Unlike a conventional city, the smart city actually means a "digital" city - a concept that has so far no unambiguous definition. Experts' views, however, are united in the fact that a smart city should not be perceived in the narrow sense as a city packed with technology. The technologies in this case are rather a means of achieving a common goal, namely the creation of a comfortable urban environment. Structurally, the "smart" city is a system of interacting systems. Such interaction of a huge number of systems requires openness and standardization, which are the basic principles of creating smart cities. A "smart city" project, lacking openness and standardization, is soon becoming clumsy and expensive. Some of the technologies involved and defining smart city are highspeed optical, sensor, cable and wireless networks necessary for the realization of the benefits achieved thanks to intelligent transport systems, smart electrical networks and smart home networks [5]." The "smart cities" is a new concept and it measures not how smart the city is, but the city's efforts to make itself smart — sustainable development, sound economic growth, and when the urban system adapts itself to the users' needs. The smart city concept incorporates good urban planning, use of digital technologies, networks of technologies, networks of people who work together well, a change in the way of thinking, the transformation of the city governments for successful smart cities and applying the participatory approach [6]. The smart region really means the "digital" region - a concept that has no clear definition so far. However, experts agree that the smart region should not be seen in a narrow sense as a technology packed region. Rather, technology in this case is a tool, an instrument for achieving a common goal, namely the creation of a comfortable regional environment. In our opinion a Smart Region is a large area, of mixed urban and non-urban use, where smart technologies have been deployed to benefit the economic growth, quality of life and wellbeing of citizens in the territory in 
connection with sustainable development and climate changes. Making a region "smart" is most often based on implementing urban innovation in three main areas. These are transport to improve residents' mobility and reduce congestion by offering alternative modes of transportation, an environment that includes water management, energy, air quality and waste, and the overall improvement of the lives of people who they live in the city [7]. The adoption of the knowledge as a resource, such as the material, energy and financial resources of the enterprise, as well as its optimization and utilization, provide a competitive advantage for the organization. In addition, knowledge is a highly liquid resource that can easily be transferred to a product and / or traded, but is an asset that ages rapidly in today's dynamic conditions of development of science and information and communication technologies, which determines the need for permanent investment in training and enhancing the skills and competencies of the employees of each organization in order to increase competitiveness. A turbulent environment requires and forces the organization to generate and have the necessary knowledge to be flexible and to have the ability to react quickly and adequately to emerging changes. The accumulation of knowledge in the organization is the result of the ongoing process of training and accumulation of experience by the organization's employees, but they can be lost immediately by leaving, retiring or "internally displacing" capable employees. The transformation of knowledge into assets requires, it to be preserved, shared and transferred, integrated into the business processes, management practice and culture of the organization[8]. But for the creation of the smart region really means "the "digital" region - a concept that has no clear definition so far. However, experts agree that the smart region should not be seen in a narrow sense as a technology-packed region. Rather, technology in this case is a tool, an instrument for achieving a common goal, namely the creation of a comfortable regional environment. In our opinion a Smart Region is a large area, of mixed urban and non-urban use, where smart technologies have been deployed to benefit the economic growth, quality of life and wellbeing of citizens in the territory in connection with sustainable development and climate changes. Making a region "smart" is most often based on implementing urban innovation in three main areas. These are transport to improve residents' mobility and reduce congestion by offering alternative modes of transportation, an environment that includes water management, energy, air quality and waste, and the overall improvement of the lives of people who they live in the city"[9]. The presentation of the opportunities for planning and implementation of projects in order to improve the socio-economic conditions in the small municipalities is ,directly dependent on the spatial planning on the one hand, and on the other hand on the planning of specific measures to be implemented in the next programming period 2021-2027. In hierarchical terms, spatial planning on the territory of the country covers three levels, namely national, regional and local or even spatial planning, which refers to particular individual settlements (mainly municipalities). We can say that our country is late in adopting concepts of spatial development because at national level, a National Concept for Spatial Development was adopted in 2012, which lays down some of the basic principles of spatial planning in the European Union and at the same time it is perceived as the first document of its kind in the country that has been prepared and adopted in the last three decades. The elaborated National Spatial Development Concept replaces the complex national spatial planning scheme provided by the Spatial Planning Act, while regional planning according to the Spatial Planning Act provides for the elaboration of regional concepts and spatial planning schemes from which one was drawn up with a range of five 
municipalities until the adoption of the National Concept. However, when we take a snapshot in a structural and content plan at a local level, regarding the availability of municipal spatial planning plans, we can see that fewer than half of Bulgarian municipalities have such, but of course the situation is different when we look at the existence of elaborated and adopted municipal development plans, which obligation is imputed and regulated by the Regional Development Act. According to the signed Toledo Declaration in 2010, which focuses on the implementation of an integrated approach to planning the development of European cities, the Ministry of Regional Development introduces a new planning tool with the idea of integrating different sectors of urban development in Bulgaria by launching procedures for the elaboration of Integrated Urban Plans reconstruction and development developed in accordance with the Regional Development Act. In general, we can state that the purpose of these plans is to make them an integral element between development plans and development plans at the local level [10], [11]“.

\section{Discussion}

This study aims to provoke a scientific discussion on the future socio-economic recovery and development of lagging regions in the Republic of Bulgaria, as on the one hand it can't yet be declared that the pandemic has been controlled as a result of COVID-19, on the other hand, we cannot unambiguously determine the socio-economic consequences for the individual regions of the country as a result of it. In this context, the territorial units should consider the possibilities for taking proactive measures and formulating recovery policies, plans and strategies, which may include the use of public-private partnership opportunities on the one hand. On the other hand, individual municipalities may consider cooperating to create comparative competitive advantages and attract strategic investors in the socio-economically lagging regions of the country. Certainly, individual regions should not rely solely on the opportunities provided for the use of direct funding from European Union funds and programs. And they need to prepare timely strategies and plans to support local businesses and to attract strategic investors in their territory. A number of discussion issues remain unresolved, one of which is: What approaches, techniques, models can be used by the administrative-territorial units for their faster socio-economic recovery and the creation of appropriate conditions for attracting foreign direct investment on their territory?

\section{CONCLUSION}

The continuing deepening of the socio-economic differences between the different regions of the country shows that the well-developed administrative-territorial units are limited compared to the lagging regions in the country. Indicative of the existence of large disparities in the development of the country is the development of the capital and the South-Western planning region, where in fact almost 50\% of the country's GDP is concentrated. At the same time, the socio-economic development of the other alternative economic centers and balancers of the capital, namely the cities of Plovdiv, Varna and Burgas, is significantly lagging behind. On the other hand, there has been an increase and deepening of social and demographic problems in a number of regions, which unequivocally shows that the regional policies pursued so far have had a contradictory result, which is dictated on the one hand by the way decisions are made by the bodies of the central executive power, which often excludes the local government from the process of planning and decision-making regarding the conducted regional policy in the country. 
In the next programming period, it is extremely important for the central executive to focus on the problems of the lagging administrative-territorial units, which must be purposefully financed and assisted in their struggle to recover from the socio-economic crisis they will face as a result of the pandemic caused by COVID-19. In addition, undoubtedly a national priority for the next decade must be to take measures and plan policies to deal with the demographic crisis or at least to keep the economically active population in the lagging socio-economic administrative-territorial units of the country. The displacement of large masses of young people from the villages aggravates the age structure of the rural population and improves the age structure of the urban population. Migration of young people from these settlements leads to reduced economic potential and worsening demographic potential [12]. "Due to the economic crisis, the situation of immigrants in Europe at this time is particularly difficult. One of the most frequent reasons for immigration is the demand for employment, but as employers usually dismiss first employees and workers, the most severe consequences of the economic downturn are felt by immigrants, especially in the countries hardest hit by the crisis" [13]. Certainly, the resolution of the problems arising from the COVID-19 pandemic requires states to "recognize the links between the promotion of universal health coverage and other foreign policy issues, such as the social dimension of globalization, cohesion and stability, inclusive and equitable growth and sustainable development and sustainability of national financing mechanisms, and the importance of universal coverage in national health systems"[14]. A global pandemic Covid-19 led countries to take aggressive action regarding social management and crisis governance management system. The case of a pandemic discovered in Wuhan provides a lesson for the government worldwide to adopt. However, the government system in every country has its characteristics. The strengthening country's capacity system is vital in the regional autonomy system as well as the collaboration between central and local government in terms of containment of the spread of the pandemic. The biggest challenge in a decentralized government system that arises is that the administrative system that is tiered from the central government to the lowest level of government has caused a miss communication between regions[15]. In this case "frame in global health governance is an important issue in a case of pandemic disease because when a frame has been raised, the policy response that arises will also lead to the existing structure"' [15][16].

\section{REFERENCES}

[1] Zlatunova, D., Babukova, P., Integrated vulnerability analysis for disasters risk reduction, International Scientific Conference GEOBALCANICA, 2016, available to https://www.researchgate.net/publication/307940747_INTEGRATED_VULNERABILITY_AN ALYSIS_FOR_DISASTERS_RISK_REDUCTION on 04.03.2021

[2] Zlatunova, D., Babukova, P., Challenges ahead the creation of geo databases for multi-risk assessment in Republic of Bulgaria, International Scientific Conference GEOBALCANICA, 2016, available to https://www.researchgate.net/publication/307940506_CHALLENGES_AHEAD_THE_CREAT ION_OF_GEO_DATABASES_FOR_MULTI-

RISK_ASSESSMENT_IN_REPUBLIC_OF_BULGARIA on 04.03.2021

[3] Colbourn, T. COVID-19: Extending or relaxing distancing control measures. Lancet Public Health 2020, 5, e236-e237. 
[4] Sarbast Moslem, Tiziana Campisi, Agnieszka Szmelter-Jarosz, Szabolcs Duleba, Kh Md Nahiduzzaman, and Giovanni Tesoriere, Best-Worst Method for Modelling Mobility Choice after COVID-19: Evidence from Italy, available to https://www.mdpi.com/2071$1050 / 12 / 17 / 6824 / \mathrm{htm}$ on 18.04 .2021

[5] Naydenov, K1., Smart cities - the future of urban planning, 5th SGEM International Multidisciplinary Scientific Conferences on SOCIAL SCIENCES and ARTS SGEM2018, available to https://www.researchgate.net/publication/329929803_SMART_CITIES__THE_FUTURE_OF_URBAN_PLANNING on 03.02.2021 .

[6] Atanasova A., Naydenov K. (2020) The Innovative Approaches for the Development of Smart Cities. In: Nedkov S. et al. (eds) Smart Geography. Key Challenges in Geography (EUROGEO Book Series). Springer

[7] Naydenov, Kl., Smart regions - opportunities for sustainable development in the future, International Scientific Conference GEOBALCANICA, 2020, available to http://geobalcanica.org/wp-content/uploads/GBP/2020/GBP.2020.62.pdf on 18.04.2021

[8] Naydenov, Kl., Prospects for knowledge management in public sector organizations, 5th SGEM International Multidisciplinary Scientific Conferences on SOCIAL SCIENCES and ARTS SGEM, 2018

[9] Naydenov, Kl., Smart regions - opportunities for sustainable development in the future, International Scientific Conference GEOBALCANICA, 2020, available to http://geobalcanica.org/wp-content/uploads/GBP/2020/GBP.2020.62.pdf on 03.03.2021.

[10] Ivanov, M., Naydenov, Kl., The strategic spatial planning as a tool for encouraging the regional development in Bulgaria, ANNUAL OF THE UNIVERSITY OF MINING AND GEOLOGY "ST. IVAN RILSKI", Vol. 59, Part IV, Humanitarian sciences and Economics, 2016

[11] Ivanov, M., Problems in the formation of policies for sustainable development and the use of public-private partnerships in the border municipalities between the Republic of Bulgaria and the Republic of Serbia, 20th International Multidisciplinary Scientific GeoConference Proceedings SGEM, 2020, DOI: 10.5593/sgem2020/5.2/s21.049

[12] Naydenov, Kl., T. Traykov, Demographic situation in urban areas of Republic of Bulgaria in the last 25 years, 1st International Scientific Conference Geobalcanica , 2015, DOI: http://dx.doi.org/10.18509/GBP.2015.27 UDC: 314.911.375(497.2) „1990-2015

[13] Naydenov, Kl., Regional image - a prerequisite for economic development, ANNUAL OF THE UNIVERSITY OF MINING AND GEOLOGY "ST. IVAN RILSKI", Humanitarian sciences and Economics, 60, 2017

[14] Global health and foreign policy (A/67/L.36, para. 3), 12 December 2012, available to https://ncdalliance.org/sites/default/files/resource_files/Global\%20Health\%20and\%20Foreign\% 20Policy\%20resolution\%202012_67th\%20GA.pdf on 18.04.2021.

[15] Agus Supriyadi, Tao Wang, Pandu Pribadi, M. Ali Mauludin, Faqih Ma'arif, Zalik Nuryana, A review of institutional response and Covid-19 pandemic risk communication in regional autonomy system in Indonesia, International Journal of Communication and Society, ISSN: 2684-9267 Vol. 3, No. 1, June 2021, pp. 39-51

[16] C. McInnes and K. Lee, "Framing and global health governance: Key findings," Glob. Public Health, vol. 7, no. SUPPL. 2, 2012. 